\section{Palobra}

ACCESO 2 ABIeRTo

Cómo citar: Araya, M., \& Rojas, M. (2021). Organización comunitaria frente a las lógicas del desarrollo: resistencia en defensa de los bienes comunes en los casos de Playa Potrero y la Zona Protectora El Chayote. Palobra, 21(1), 96-116-. https://doi.org/10.32997/23462884-vol.21-num.1-2021-3489

Recibido: 14 de diciembre de 2020 .

Aprobado: 23 de abril de 2021.

Editor: Ricardo Chica Gelis. Universidad de Cartagena-Colombia.

Tipología IBN Publindex:

Artículo de reflexión.

\title{
Organización comunitaria frente a las lógicas del desarrollo: resistencia en defensa de los bienes comunes en los casos de Playa Potrero y la Zona Protectora El Chayote
}

\author{
Community organization facing the logic of development: \\ resistance in defense of common goods in the cases of Playa \\ Potrero and the El Chayote Protective Zone
}

\author{
María Andrea Araya Carvajal ${ }^{1}$ \\ Universidad de Costa Rica, MARIAANDREA.ARAYA@ucr.ac.cr \\ Marco Rojas Lizano ${ }^{2}$ \\ Universidad de Costa Rica
}

\begin{abstract}
RESUMEN
La organización comunitaria es una de las formas que generan resistencia frente a las dinámicas del capitalismo que observan en los recursos naturales una fuente del crecimiento económico. Estas clases se han valido del discurso del desarrollo sostenible para permitir la expansión de los límites del capital sin contemplar el desgaste y agotamiento del medio ambiente. Sin embargo, existen comunidades que luchan contra estos tipos de explotación, dando espacio a otras formas de habitar y convivir en comunidad. Este es el caso de organizaciones comunitarias de localidades como Naranjo y Playa Potrero en Santa Cruz, que generaron estrategias para la protección del agua y la autonomía de su gestión. Se pretende, entonces, recuperar la memoria histórica de procesos de organización en estos conflictos socioambientales y analizar las contradicciones de los discursos de desarrollo planteados en Costa Rica. Para ello, se utiliza la información recopilada a partir del trabajo de campo, utilizando herramientas como entrevistas semiestructuradas y abiertas a participantes de estos movimientos comunales. Dentro de las principales conclusiones se encontró que los afectos por la tierra y el desencanto con las propuestas del desarrollo turístico y los grandes capitales, son los que mueven a las personas a organizarse y proteger a lo que consideran bienes comunes.
\end{abstract}

Copyright: () 2021. Araya, M., \& Rojas, M. Este es un artículo de acceso abierto, distribuido bajo los términos de la licencia
https://creativecommons.org/licenses/bync-sa/4.0/ la cual permite el uso sin restricciones, distribución y reproducción en cualquier medio, siempre y cuando que el original, el autor y la fuente sean acreditados.

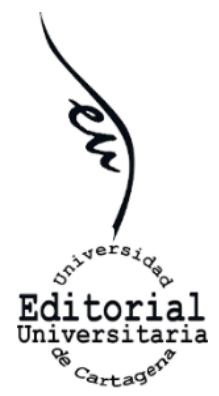

Palabras clave: Comunidad; desarrollo sostenible; memoria histórica; agua; movimiento social.

\begin{abstract}
Community organization is a way to resist in front of capitalism and its dynamics that exploits natural resources for the enrichment of hegemonic classes. These classes have used the sustainable development discourse to allow the expansion of capital without considering the tear of the environment. However, facing this situation, there are experiences giving space to other possible ways of living and
\end{abstract}

${ }^{1}$ Docente e investigadora de la Carrera de Psicología, Sede de Occidente, Universidad de Costa Rica.

2 Docente, Carrera de Psicología, Sede de Occidente, Universidad de Costa Rica. 
organizing in the community. This is the case of two community organization located in El Chayote in Naranjo and Playa Potrero in Santa Cruz. Both communities developed strategies for the protection of water and its autonomous management. The present article intends to recover the historical memory of community processes around these socio-environmental conflicts and to analyze the contradictions of development discourses raised in Costa Rica. This paper is based on a three years field work investigation, using qualitative techniques such as semi-structured and open interviews with people from the communal movements. Among the main conclusions, it was found that affection for the land and disenchantment with the models proposed by tourism development and large capitals, are those that move people to organize and protect what they valued as common goods.

Keywords: Community organization; Sustainable development; Historical memory; Water; Social movement.

\section{INTRODUCCIÓN}

A lo largo de Latinoamérica, encontramos una serie de experiencias en las que se resalta cómo las comunidades han optado por organizarse, para resistir a formas de acumulación de capital a partir de la explotación de los recursos naturales. Estas lógicas de explotación se han abierto camino valiéndose de adjetivaciones que les permiten eximirse de culpas por las catástrofes ambientales o bien por la escasez, distribución y acceso de los recursos naturales.

El presente texto recoge parte de las experiencias vividas por distintas personas, actores y actrices comunitarias, en procesos de organización para la defensa de sus recursos naturales, amenazadas por las lógicas del mercado representadas en la inversión privada, de la mano y respaldo de la institucionalidad del Estado. Particularmente, analizamos las acciones de organización comunitaria en la Comisión para la Defensa de la Zona Protectora El Chayote en el cantón de Naranjo y de la ASADA de Playa Potrero, en Santa Cruz 3 .

El texto pretende generar reflexiones y problematizaciones sobre las formas de desarrollo, tanto económico como humano, planteadas en Latinoamérica desde la década de los 70, sobre el desarrollo sostenible. Además, planteamos un acercamiento a las dinámicas de las instituciones estatales de Costa Rica en relación con su funcionamiento y el cuido del medio ambiente frente a las presiones de intereses privados.

Con esto pretendemos contribuir a la recuperación de la memoria histórica de estas organizaciones comunitarias, las cuales tuvieron una gran cobertura mediática, por ejemplo, en el caso de Playa Potrero, para que sirvan de base para el análisis de futuros conflictos socioambientales en el marco de una economía voraz que avanza en su proyecto de mercantilización de la vida cotidiana.

\footnotetext{
${ }^{3}$ Este artículo es parte de los resultados de la investigación trabajada en la carrera de Psicología en la Sede de Occidente de la Universidad de Costa Rica denominada "Procesos de lucha y organización comunitaria para la gestión del recurso hídrico: sistematización de experiencias y saberes la Comisión para la Defensa de la Zona Protectora El Chayote (CDZPEC) en Naranjo y la ASADA de Playa Potrero en Santa Cruz" desarrollado entre el 2016 y 2018.
} 
Se trabaja desde un enfoque cualitativo, fundamentado en la investigación participativa y el análisis de discurso. Durante el proceso se entrevistó a 23 personas de las comunidades de Playa Potrero y Naranjo, en relación con la organización comunitaria por la defensa del agua. Los resultados apuntan a que la organización comunitaria para defender el agua como recurso común tiene resultados tangibles y se presentan como formas de resistencia ante el avance de un desarrollo que supone el despojo de los grupos más vulnerados social y económicamente.

\section{Contextualización de los colectivos comunitarios}

Esta breve contextualización de cada colectivo, lejos de realizar comparaciones jerarquizantes u homogenizantes, pretende rescatar sus características comunitarias, geográficas, climatológicas, hidráulicas, sociodemográficas, que, aunque son disímiles, ambas cuentan con un lugar común: la decisión de organizarse y luchar por el cuido y la gestión de los recursos naturales comunitarios.

Partimos de que, en el intento de acercarse a los procesos comunitarios en espacios diferentes, se deben entender las particularidades históricas de cada uno, así como las circunstancias de su conformación e historia de las agrupaciones. Si bien entendemos que cada agrupación tiene características y circunstancias en que se distinguen, también encontramos que han atravesado fenómenos similares, de los que se desprenden aprendizajes gestados en las experiencias de resistencia de las organizaciones comunales.

\subsection{Comisión para la Defensa de la Zona Protectora El Chayote}

La Zona Protectora El Chayote, toma su nombre de origen popular gracias a las chayoteras ${ }^{4}$ que se encontraban en sus inmediaciones. Dicha zona cuenta con una gran biodiversidad, ya que se ubica justamente como un corredor biológico entre los parques nacionales Juan Castro Blanco y el Volcán Poas. Es importante rescatar que, dadas sus características topográficas, a lo cual se suma la presencia de ceniza volcánica, sus suelos carecen de las capacidades necesarias para el desarrollo de actividades agrícolas, razón por la cual se ha argumentado la necesidad de que estas tierras sean dedicadas exclusivamente para la expansión forestal (Piedra y Rojas, 2011).

Las acciones de protección de El Chayote nacen en el marco de la coyuntura histórica costarricense hacia finales de los años setentas, en la cual a nivel de gobierno se empieza a dar un auge en la protección de los recursos naturales. En el año de 1984, en Naranjo, iniciativas locales buscan establecer parámetros legales para la protección de este recurso boscoso de la parte alta del cantón, el cual se estaba viendo amenazado por incendios, provocados en la mayoría de casos, por las prácticas en agricultura que incluían las quemas como mecanismo para la rotación de suelos y cultivos (Piedra y Rojas, 2011).

\footnotetext{
${ }^{4}$ Enredaderas de la planta del chayote.
} 
En el año 2010, se da una alarma comunitaria ante la posibilidad de un cambio en los límites de la zona, generando que diversas organizaciones y fuerzas vivas del cantón lograran una amplia convocatoria en el gimnasio de la Escuela República de Colombia para la discusión de las posibles amenazas y de la forma en la cual procederían para evitar la reducción de la zona ${ }^{5}$.

Una vez revisada la información y gracias a la experticia en cartografía de algunos vecinos y vecinas, estos se dan cuenta que lo que pretendían las instancias institucionales en realidad era una corrección de la delimitación planteada, ya que una de sus coordenadas estaba extraviada y se ubicaba cerca de Honduras (Entrevista personal 2, - Naranjo, 2017).

Sin embargo, esta reunión no sería en vano, ya que activó una serie de mecanismos comunitarios para la defensa de los recursos naturales del cantón, principalmente aquellos ubicados en la Zona Protectora El Chayote. Justamente, para las mismas fechas de esta gran convocatoria, en la municipalidad de Naranjo se tramitaba un permiso para un parcelamiento agrícola en una parte de la Zona Protectora, el cual tenía a la vez como agenda oculta un desarrollo urbanístico ${ }^{6}$ (Entrevista personal 3, - Naranjo, 2017).

Este escenario y la necesidad de tomar medidas ante las propuestas que amenazaban con los recursos de la Zona Protectora, dieron paso a la conformación de la Comisión para la Defensa de la Zona Protectora El Chayote $(\mathrm{CDZPECH})^{7}$, la cual acogió un grupo muy heterogéneo de personas que, desde distintas ocupaciones, formaciones profesionales y tendencias políticas, se mostraron interesadas en dar un seguimiento a la discusión sobre el cuido de El Chayote (Castro, 2015).

La Comisión, tuvo como principal objetivo construir una ley que demarcara la Zona Protectora, además de establecer sus usos de suelo, evitando tener problemas constitucionales tales como los que acarreaba la creada en $1984^{8}$. De esta manera, la nueva ley permitiría tener herramientas jurídicas para hacer frente a cualquier interés particular de explotación de los recursos naturales con intereses privados o públicos en dicha zona (Entrevista personal 1, Naranjo, 2017).

Tras un arduo trabajo de las personas que integraron la CDZPECH, el cual consistió en la articulación de alianzas comunitarias con ASADAS, Asociaciones de Desarrollo, el Comité Cantonal de la Persona Joven, el Colectivo Unión Vital y el apoyo de todas las bancadas políticas de la Asamblea Legislativa, se logró en un tiempo expedito (ocho meses), la aprobación de la Ley número 9085, la

\footnotetext{
${ }^{5}$ Es importante señalar que la zona protectora contaba en un inicio con una extensión de 840 hectáreas y en el año de 1990 a través de un decreto se le redujeron 80 para dar con la actual extensión de 760 hectáreas.

${ }^{6}$ Se debe apuntar que actualmente solo 105 hectáreas de la Zona Protectora son públicas, es decir, están en manos de la Municipalidad de Naranjo o de la Federación de Acueductos Rurales del cantón, las restantes 655 están en manos privadas (Entrevista personal 3- Naranjo, 2016).

7 Página oficial de Facebook: https://www.facebook.com/Comisi\%C3\%B3n-para-la-defensa-de-la-Zona-Protectora-ElChayote-212550002140351/

${ }^{8}$ La ley de 1984 estaba sujeta a un presupuesto de la República, lo cual posteriormente fue estipulado como inconstitucional por la Sala Constitucional de la Corte Suprema de Justicia.
} 
cual saldría publicada en el diario oficial La Gaceta el 13 de setiembre del 2012 (Castro, 2015; Entrevista personal 3, - Naranjo, 2016).

Actualmente, tras un largo periodo de latencia, la CDZPECH retoma actividades ante la amenaza para la Zona Protectora propuesta en el seno del Concejo Municipal de Naranjo, de implementar una embotelladora de agua y una incineradora de residuos sólidos en el cantón ${ }^{9}$ (Entrevista personal 3, - Naranjo, 2017).

\section{2. $A S A D A^{10}$ de Playa Potrero}

La comunidad de Playa Potrero está ubicada en el distrito de Tempate, cantón de Santa Cruz. Es una comunidad pequeña, que se ha constituido principalmente alrededor de la plaza de fútbol, la cual está circundada por iglesias, tanto católicas como protestantes, además de la escuela y la mayor parte del comercio. Se destaca que esta comunidad conserva una estética rural, lo cual dista de lo observable en comunidades vecinas como Tamarindo y Flamingo, las cuales se han visto envueltas en un desarrollo inmobiliario provisto por el incremento del turismo en la zona, principalmente desde la década de 1990 (Navas y Cuby, 2015; Bolaños, 2016).

En Playa Potrero, justamente al costado oeste de la plaza de futbol, se encuentran las instalaciones de la ASADA local, la cual nace en el año de 1991 como un acueducto comunitario con el objetivo de ofrecerle a los y las vecinas un servicio de agua potable con las condiciones de salubridad necesarias, a través de la construcción de un tanque de captación y su respectivo sistema de distribución alrededor de la comunidad. Particularmente, dicho proceso constructivo fue financiado por los y las vecinas a través de diversas actividades en las que lograron recaudar los fondos necesarios ${ }^{11}$. Actualmente, la ASADA tienen bajo su administración dos tanques de agua, encargándose, además, de los procesos de desinfección y mantenimiento de la cañería (Entrevista personal 4, -Naranjo, 2016).

Pese a todo este trabajo desarrollado por los y las vecinas, que de manera voluntaria se encargaban de la gestión del agua, no fue hasta el año 2007 que se logra establecer la ASADA formalmente con la autorización del ICAA $^{12}$ (Bolaños, 2016).

En el 2014 surge una problemática en torno a la gestión del agua en esta comunidad a partir de que, si bien la ASADA contaba con el aval del ICAA, aún no se había firmado el convenio de delegación establecido por ley, pese a que este había sido solicitado formalmente en varias ocasiones (Bolaños, 2016).

\footnotetext{
${ }^{9}$ Municipalidad de Naranjo. Acta de la sesión extraordinaria N 08 del 4 de junio de 2016. Además, el día 13 de septiembre se hizo una exposición pública del proyecto por parte del presidente del concejo municipal, Orlando Herrera, la cual tuvo lugar en la Casa de la Cultura de Naranjo.

10 Asociaciones Administradoras de Sistemas de Acueductos y Alcantarillados. Estas fueron establecidas en el 2005 y funcionan de manera comunitaria a partir de un convenio de delegación del ICAA.

${ }^{11}$ Información suministrada por la ASADA de Playa Potrero.

12 Instituto Costarricense de Acueductos y Alcantarillados (ICAA). Sin embargo, a nivel popular en Costa Rica es conocido como AyA.
} 
Entonces, durante ese año y a partir de la queja de una vecina presentada a la Sala Constitucional por una inconformidad con el servicio prestado por esta ASADA, esta instancia dictamina que ICAA es el ente que debe encargarse de la administración del acueducto. Es por esto, que a la hora de hacer efectiva la orden de la Sala Constitucional, el ICAA, acuerpado por un despliegue policial de alrededor de 70 antimotines, toma de manera violenta las instalaciones de la $\mathrm{ASADA}^{13}$, las cuales posteriormente fueron recuperadas a través de un dispositivo comunitario de participación y acompañamiento de quienes integraban formalmente la administración del acueducto. Escena que, sin embargo, se repite en varias ocasiones (Entrevista personal 4 Potrero, 2016).

Podemos decir que, dentro de las principales acciones llevadas a cabo por la administración de la ASADA y los diversos actores comunitarios, está la articulación de las fuerzas vivas de Playa Potrero, a través de un núcleo conformado por integrantes de distintas organizaciones como Asociación de Desarrollo Integral, el Instituto de Oceanología ${ }^{14}$, muchos vecinos y vecinas, así como otros colectivos sociales, tanto de Potrero como de lugares aledaños, quienes lograron el establecimiento del convenio de delegación con el ICAA.

\section{Discurso del desarrollo y su impacto en las comunidades}

Iniciamos con un acercamiento a algunas nociones de desarrollo presentes en Latinoamérica. El discurso desarrollista es aquel que pretende realizar una homologación entre el crecimiento económico cuantificable y el mejoramiento de las condiciones de vida de las poblaciones (Harvey, 2014). La concepción clásica de desarrollo, siguiendo a Sunkel (1970), se ha entendido en relación con el crecimiento, y asociado al concepto de ingreso por habitante. También se asocia con la inversión, el financiamiento externo, los criterios de prioridad en la asignación de recursos, la movilización de los ahorros internos, entre otros. Asimismo, según este autor, el desarrollo pone énfasis en los instrumentos de poder político y en las estructuras sociales de poder, ya que es a través de estas desde las que se construyen estrategias para motivar las aspiraciones sociales y la cultura nacional, asociándolas con fortalecimiento y enriquecimiento.

En síntesis, esta forma de concebir el desarrollo supone que este refiere a un proceso de cambio social deliberado que tiene como finalidad última la igualación de oportunidades sociales, políticas y económicas, tanto en el plano nacional como en relación con sociedades internacionales que poseen patrones más elevados de bienestar material (Sunkel, 1970).

Un término que se deriva del anterior es el de subdesarrollo, desde el cual se parte de que todo lo que no se ajusta al modelo desarrollista se considera un retraso, que explica por qué las personas, o países están en malas condiciones socioeconómicas. En esta línea, los países subdesarrollados o en vías de

\footnotetext{
${ }^{13}$ Información que se puede verificar en https://www.nacion.com/archivo/vecinos-de-playa-potrero-se-oponen-a-llegadade-aya/D34RRNB33JCSLBSYIPIADQ2TBE/story/ (Ver en referencias Bran, Cinthya).

14 “El Instituto de Oceanología de Costa Rica se creó en el 2012. Tiene por objetivo realizar acciones de conservación de la biodiversidad en los ecosistemas marinos y costeros costarricenses." Información tomada de la página de Facebook https://www.facebook.com/InstitutoDeOceanologia/
} 
desarrollo, son los que cuentan con potencial de desarrollo, pero que a su vez ese potencial se da por un vínculo de dependencia de los países (¿auto?) denominados desarrollados. En ese sentido, los grupos nacionales o extranjeros que tienen posibilidades de generar inversiones son quienes representan las vías de desarrollo frente a aquellos grupos que por sus condiciones pasan a convertirse en fuerza de trabajo para la acumulación capitalista (Quijano, 2000; Mota y Sandoval, 2016).

Ante esta realidad, el crecimiento económico no se puede establecer como equiparable al bienestar comunitario ni al personal. América Latina, región que se ha considerado subdesarrollada, especialmente en comparación con Estados Unidos y los países de la Unión Europea, ha sufrido los embates del modelo desarrollista desde hace muchas décadas. Se supone que, invariablemente, esta región tiene que "transitar por los mismos caminos de los países desarrollados" (Gligo, 2007, p. 17), para alcanzar el objetivo último que es ese -y ningún otromodelo de desarrollo. Aproximadamente desde la década de los noventa, esta región se convirtió en destinataria preferencial de la inversión extranjera directa y desde ese momento este fenómeno se ha dado de manera sostenida. Esta inversión ha significado, en muchas ocasiones, la explotación excesiva de los recursos naturales renovables y no renovables con las múltiples y dañinas consecuencias que esto implica (Gligo, 2007).

En relación con lo anterior, dentro de los sectores que más han generado inversiones extranjeras en América Latina, se encuentran los relacionados con la apropiación de recursos naturales que suelen ser abundantes en esta región, por ejemplo, agua, petróleo, minerales, tierra (para agricultura), entre otros (Giarracca, 2007). Costa Rica se encuentra entre los países latinoamericanos en que más se han desarrollado este tipo de inversiones (Suanes, 2016), las cuales generalmente son de carácter privatizador y extractivista ${ }^{15}$.

Uno de los resultados de lo anterior es el impacto directo en la desigualdad de ingresos en las economías de la región, en especial, para algunos sectores (Suanes, 2016). Un ejemplo de esto, específico para Costa Rica, es el sector turismo, puesto que, desde finales del siglo XX, se convirtió en la primera fuente de divisas del país (Chen, 2015).

Dentro de las regiones en que se ha generado más desarrollo del sector turismo, y por tanto los que han recibido mayor inversión extranjera, se encuentran los distritos del Pacífico Central y Norte: en especial Santa Cruz, Puntarenas, Carrillo, Golfito, Nicoya, Tilarán, Garabito, Aguirre, Pérez Zeledón y Bagaces, en ese orden de mayor a menor cantidad de inversión. Entre esas inversiones se pueden mencionar hoteles como Los Sueños Marriott, Reserva Conchal, Hacienda Pinilla, JW Marriott, Four Season, Hilton y Hyatt, pero también, cada vez en mayor medida, se da la compra de tierras para uso privado, como construcción de viviendas, construcción de condominios, establecimientos comerciales, etc. (Chen, 2015).

\footnotetext{
${ }^{15}$ Los casos que se analizaron en esta investigación responden a este tipo de inversiones (Playa Potero con el turismo y la privatización de acceso al agua, y, El Chayote con el intento de apropiación de tierras protegidas para la urbanización).
} 
Si se contrastan los datos anteriores con los indicadores de pobreza reportados para Costa Rica por el Instituto Nacional de Estadística y Censos (INEC) en los años 2010 y 2018, queda en evidencia como dicha inversión no ha tenido una disminución marcada en este sentido, considerando la cantidad de inversiones de capital reportadas en la región, que ya tiene cerca de tres décadas. En el informe de la Encuesta Nacional de Hogares (ENAHO) de 2010 se indica que, en la región Chorotega, donde se ubica Santa Cruz (ahí pertenece Playa Potrero), el índice de pobreza estaba en 32,6\%, mientras que en el 2018 se reporta un $26 \%$. Para la ENAHO del 2019, la pobreza multidimensional (incluye educación, acceso a vivienda, salud, trabajo y protección social), reportó un $18,8 \%$, pero con una intensidad de 27. La intensidad de la pobreza multidimensional refiere a la profundidad con que dicha pobreza es experimentada en los hogares que la sufren, lo que significa que cerca del $20 \%$ de la población en dicha región se encuentra en condiciones de pobreza y es una de las tres regiones del país con mayor intensidad en la pobreza, pues el promedio del país es de 26,8 .

Por tanto, los datos anteriores reflejan una realidad contraria a la que promueven los discursos desarrollistas: el crecimiento económico, que supone una igualdad en las oportunidades que permitan mejor calidad de vida mediante el ingreso económico, que evidentemente no es el caso para las regiones estudiadas, ni en general, para el país. A pesar de las inversiones, algunos grupos dentro de las comunidades han desenmascarado las lógicas falaces de estos desarrollos, mediante la organización y lucha para proteger los recursos comunes frente al extractivismo del modelo.

\subsection{Impacto del modelo desarrollista en las comunidades}

En relación con las afectaciones que genera el modelo descrito, en el caso de las organizaciones comunitarias de Playa Potrero y Naranjo, las personas entrevistadas aseguran que estas tienen una connotación negativa, ya que vulneran las condiciones de bienestar de quienes habitan estos espacios. Ubicándola en estas comunidades, la noción de desarrollo, no se aleja del escenario que se ha mostrado en América Latina.

A partir de la argumentación de las y los vecinos de estas comunidades, se puede sintetizar esta noción de desarrollo como las acciones para la generación de infraestructura (o capital) a costa del aprovechamiento de los recursos comunitarios (ambientales, mano de obra, servicios, etc.). Esta explotación de recursos que en el caso de Potrero proviene de una inversión privada y cuenta con el aval de la institucionalidad que representa al Estado. Estos inversores o bien, "desarrollistas", son aquellos que se posicionan frente a las personas que conforman la comunidad con un discurso que apela a la oferta de empleo, el mejoramiento de los servicios locales, la atracción de turismo y otras propuestas que prometen solventar diversas necesidades, todo esto, sin embargo, a partir de la apropiación de bienes comunes como, por ejemplo, el agua.

En el caso de la CDZPECH uno de sus integrantes hace uso del tema del desarrollo de la siguiente manera: 
[lo que] activó todo fue como una especie de desarrollo urbanístico que se quiso desarrollar en la Zona Protectora El Chayote que como le decía, es una zona de alta vulnerabilidad ambiental, esto, como ya se conocían otros casos a nivel nacional, en otras regiones del país, se quiso utilizar la figura de fraccionamiento agrícola para empezar a hacer ese desarrollo, a permitir como que se meta alumbrado público, electricidad y otros servicios que en este momento no hay ahí arriba en la Zona Protectora y que es como el inicio del final de esas zonas de protección (Entrevista personal 2-Naranjo, 2016).

En la situación vivida en Naranjo, la amenaza se dio a través de la estrategia de ciertos inversionistas que, bajo la premisa de generar parcelas agrícolas en la Zona Protectora ${ }^{16}$, disfrazaron una agenda oculta que pretendía la construcción urbanística. Con base en las experiencias previas que los actores comunitarios citan sobre la realidad nacional en cuanto a procesos de desarrollo inmobiliario de este tipo, se generaron alertas por las condiciones en las que se vulneraban los recursos naturales, en este caso, por la cercanía entre los mantos acuíferos y los tanques sépticos de las posibles casas por construirse.

Además, dicha situación inserta la visión del capital, la cual observa estas zonas protectoras como tierras ociosas, recursos por explotar y que, por tanto, se deben poner a producir, en contra de las luchas y defensas que se dan colectivamente (Harvey, 2014), específicamente en este caso, en contra de la implementación legal de una declaratoria de protección de la zona conocida como El Chayote para el caso de Naranjo.

Por otro lado, en el caso de Playa Potrero y sus vecinos, el tema del desarrollo estuvo ligado siempre a la expansión de infraestructura inmobiliaria, producto, como bien lo señala Chen (2015) y Blanco (2016), del boom turístico a partir de la década de los noventas, el cual dio paso a la transformación del sector productivo de la costa guanacasteca.

Específicamente en esta comunidad se hizo mención reiteradas veces, en las narraciones de los y las vecinas, sobre el proyecto Las Catalinas -megaproyecto turístico y residencial-, el cual se ubica a escasos $4 \mathrm{~km}$ del centro de Playa Potrero. Para los entrevistados esta es una de las mayores instancias a la cual se le atribuye la explotación de los recursos naturales, particularmente aquellos relacionados con el ciclo del agua, que ponen en peligro el acceso a este recurso.

Los vecinos se refieren a Las Catalinas como un desarrollo en los siguientes términos:

...tenemos un desarrollo en Las Catalinas y ellos construyen en verano, invierno, ellos están en los años sesenta, setenta, para ellos no hay cambio climático, ellos además destruyen las zonas de recarga, lo primero que cortan son los árboles, cómo vamos a darle vida más al manto, con qué vamos a desarrollar sino hay agua, si lo primero que hacen es destruir lo que produce el agua (Entrevista personal 7-Playa Potrero, 2016)

\footnotetext{
${ }^{16}$ Se entiende una parcela agrícola como una finca que mide entre 1 y 5 hectáreas y se utiliza para para fines agrícolas.
} 
...de Las Catalinas, lamentablemente no hemos tenido ni un solo beneficio, nos cambiaron dos playas, nos cambiaron un acceso, se puede decir que público, o un acceso que se puede decir más bien, como una servidumbre de paso, que así les llamaban antes, por un acceso que no tiene nada que ver, nos cerraron Playa Dantita y Playa Danta (Entrevista personal 10Playa Potrero, 2016)

En estas narraciones podemos observar cómo se ha generado una expansión del capital de inversión turística que se ha apropiado de los recursos comunitarios, bajo la premisa de un supuesto desarrollo sostenible. Profundizando en estas, se parte de que el despliegue teórico y la puesta en práctica política del desarrollo sostenible empieza a tomar fuerza a inicios de la década de los setentas, a partir de la Conferencia de Naciones Unidas sobre el Medio Ambiente celebrada en Estocolmo, tratando de posicionar una agenda para establecer mecanismos de producción que evitaran o al menos amortiguaran, el desgaste y agotamiento de los recursos naturales (Mota y Sandoval, 2016).

Una visión crítica del discurso del desarrollo sostenible sostiene que este justamente surge como una forma de reconocimiento de la naturaleza y su papel en el proceso de desarrollo capitalista, en donde la crisis ambiental era (o es) producto de la irracionalidad ecológica en los patrones de consumo, e intentando con esto marcar los límites del crecimiento económico (Leff, 2004).

Entonces frente a esto y a los escenarios descritos, principalmente el de Playa Potrero, se pone en relieve la disputa ideológica por los sentidos o nociones que contiene la propuesta del desarrollo sostenible, de tal manera que, los resultados de las crisis ambientales nunca sean cobrados al capital, sino que los sufren directamente las personas y comunidades, evitando así cualquier fractura en el discurso hegemónico. En concordancia con la anterior, Leff (2004) argumenta que

La retórica del desarrollo sostenible es fundamentalmente una estrategia de poder que transfiere el control de la producción de la teoría a un dispositivo ideológico. Esta operación simbólica funciona dentro de los aparatos ideológicos del capital transnacional buscando legitimar las nuevas formas de apropiación de la naturaleza a las que ya no sólo podrían oponerse los derechos tradicionales a la tierra, el trabajo o la cultura (pág. 128).

Mediante esta apropiación ideológica que hace el capital del discurso del desarrollo sostenible, se libera a sí mismo de culpa, como ya lo mencionamos, permitiendo convertir la naturaleza y nuestro espacio vital en mercancías, en donde los asuntos medioambientales son concebidos como un área de actividad empresarial (Harvey, 2014).

Para ubicar lo anterior, tomamos el ejemplo de desarrollo que promueve un proyecto como Las Catalinas. En su sitio web describen sus construcciones como: "un nuevo y refrescante paradigma para crear comunidades sostenibles construidas para prosperar". Continúan su presentación: "Nuestra forma de vivir debería ser ecológicamente sostenible. Debería ser saludable, disfrutarnos siendo 
físicamente activos. Esto debería conectarnos con la naturaleza y conectarnos con otras personas. Esto debe celebrarse y deleitarse con la belleza". Además, en torno, por ejemplo, a sus métodos constructivos argumentan que "...la madera y otros materiales usados en construcción son adquiridos desde fuentes sustentables. Las edificaciones son diseñadas para ser muy eficientes energéticamente. El uso del agua debe ser eficiente" ${ }^{17}$.

Sin embargo, frente a esa "máscara verde" ubicada en su discurso, encontramos relatos de los vecinos de la comunidad de Playa Potrero que develan la falacia que intentan sostener:

...yo recuerdo que antes uno venía en las tardes a actividades de la escuela y los cerros no se veían, ahora se ven más iluminados, por lo que se ve que hay más capital extranjero, ha habido daño ambiental en algunos campos de la comunidad... (Entrevista personal 11-Playa Potrero, 2015).

Nosotros los de la Asociación de Desarrollo, le pedimos al MINAE, un inventario de árboles porque tenemos un conflicto con Catalinas... según Catalinas tienen un inventario de árboles, nosotros se los pedimos y no nos lo quisieron dar, dijeron que eso, que no querían, que no podían, daba igual porque al final no nos lo dieron y cuando fuimos a MINAE, bueno, nos salieron con unas cosas, con una corta, con una larga y el inventario de árboles no existe y supuestamente tienes que hacer un inventario de árboles antes de talar cualquier cosa (Entrevista personal 14- Playa Potrero, 2016).

...Las Catalinas cuando ellos comenzaron a construir, Diay, derribaron un montón, sinfines de árboles, y yo mandé un correo a MINAE en Santa Cruz, que nos dieran un inventario de los árboles que ellos habían permitido cortar, y lo que me supieron decir fue que, este, de que era un ignorante y que ellos no podían dar un inventario de los árboles porque ellos no sabían cuántos árboles, porque ya los árboles que ellos habían dado permiso no los tienen contabilizados, entonces le dije yo, pucha vos desde una oficina les diste el permiso de cortar cien árboles, sin saber si eran guanacaste, si eran cocobolo, si eran cenícero, yo decía pucha, si el ignorante soy yo, Diay, yo creo que de ignorante a la persona que dio los permisos le quedó grande... (Entrevista personal 10-Playa Potrero, 2016).

Con base en lo que plantean estos vecinos de Playa Potrero podemos observar cómo, mientras por un lado esta empresa expone mediante sus puntos de información sus supuestas lógicas de desarrollo que respetan y cuidan los recursos naturales, por el otro, han generado problemas con la tala de árboles en la comunidad, los cuales tienen como una de sus funciones la filtración del agua a los mantos acuíferos, lo cual a la vez se ha traducido en temor en la poblaciones sobre la posibilidades futuras del acceso al agua (Bolaños, 2016).

Por último, en estos apuntes que rescatamos de tres personas de la comunidad de Playa Potrero, se empieza a ver cómo estas dinámicas de explotación de los recursos naturales se dan con la venia de las autoridades e instituciones representantes del Estado, situación que también es descrita por los vecinos de Naranjo.

\footnotetext{
${ }^{17}$ http://www.lascatalinascr.com/en/ revisado el 23 de enero de 2019, traducción propia.
} 
Se evidencia entonces que, si bien es cierto la comunidad está lejos de ser un espacio homogéneo, como bien lo plantea Cordero (2007), en las comunidades de Playa Potrero y Naranjo existe una cohesión entre quienes habitan el espacio y comparten un sentido de comunidad (Montero, 2004), que les opone diametralmente a los desarrollistas que impulsan un modelo con intereses privados, con el aval de instancias oficiales y gubernamentales (Estado). El cuido de los recursos comunitarios se presenta con la alternativa de lucha ante la explotación ilimitada que proponen quienes vienen de afuera.

\subsection{Complicidad estatal}

Tomando en cuenta que el neoliberalismo ha intentado desaparecer las consecuencias de los problemas ecológicos, Leff (2004) propone que las políticas basadas en el discurso del desarrollo sostenible o "políticas sostenibles", tienen la función de intentar conciliar actores. Sin embargo, se debe tomar en cuenta que la desigualdad de condiciones, a partir de la tenencia de los recursos económicos, pone en evidencia desventaja a las comunidades. Y a pesar del intento de enmascaramiento que ese modelo plantea asegurando prosperidad y bienestar, quienes habitan localidades en las que se ha instalado saben que, en un corto plazo, supone lo contrario.

En Costa Rica el aparato institucional estatal funge como mediador en las disputas y tensiones surgidas entre los actores de las comunidades y los denominados desarrollistas. Pese a esto, como lo señala Harvey (2014), en el Estado capitalista, existen intereses cruzados ante la amenaza de la rentabilidad que aportarían el aprovechamiento de los recursos naturales, por tanto, suelen apoyarse y promoverse desde el Estado este tipo de inversiones.

A partir de esto, podemos observar cómo tanto en los y las vecinas de Playa Potrero como en los de Naranjo, se ha generado una desacreditación de instituciones de gobierno tales como el MINAE, SETENA, SENARA ${ }^{18}$ e ICAA, ante la falta de respuesta a las demandas planteadas. Como lo mostramos anteriormente, en el caso de los vecinos de este sector de la costa guanacasteca, prevaleció el temor a la entrada del ICAA en la administración del acueducto comunitario: “... bueno todo el mundo creía que entraba AyA, entraban los megaproyectos entonces ya no se le iba a dar importancia a la comunidad como se debía, eh, igual en general así era el pensamiento de todos en cuanto a eso y decíamos bueno una lástima, la verdad" (Entrevista personal 8- Playa Potrero, 2015).

Esta percepción de las personas se reforzaba por experiencias de localidades cercanas en las cuales el ente administrador era justamente el ICAA. Por ello, una persona entrevistada menciona: “...el fontanero, viene, es un vecino, viene a la hora que fuera, es muy colaborador, entonces arregla la fuga [En Playa Potrero], pero, por ejemplo, tú vas a Tempate, vas a Cartagena y hay fugas que tienen años de estar ahí y el AyA... "bien gracias"." (Entrevista personal 14-Playa

${ }^{18}$ Ministerio de Ambiente y Energía; Secretaría Técnica Nacional Ambiental; Servicio Nacional de Aguas Subterráneas Riego y Avenamiento, respectivamente. 
Potrero, 2016). Con esto, se denota como hay una pérdida de confianza en que el aparato estatal pueda solventar las necesidades y más bien, se parte de que lo mejor es el trabajo local.

Sumado a lo anterior, las personas perciben cómo las autoridades de las instituciones se inclinan por la inversión extranjera, mostrando una clara preferencia por estas en detrimento de la protección que se supone que brinden a sus ciudadanas y ciudadanos. Y lo relacionan con una situación de clase, que deja en evidencia irrefutable la desigualdad del modelo. Así lo explica claramente una persona vecina de Playa Potrero, reclamando que existe una limitación de permisos de construcción para personas de la zona por la supuesta falta de recurso hídrico, mientras que estos sí se conceden a grandes inversiones: “...pero lo que yo no entiendo es cómo MINAE, cómo SENARA, cómo la Municipalidad, les permiten a ellos construir cuando no tienen agua, pero Diay, a uno pobre no le permiten construir..." (Entrevista personal 10- Playa Potrero, 2016).

Por su parte, las personas que integran la CDZPECH señalan que su situación no dista mucho de la vivida en Playa Potrero. Su experiencia la relacionan con una especie de sabotaje que las mismas instituciones les hacen a las leyes del país, y a los reglamentos que regulan la urbanización de zonas protegidas, para favorecer las inversiones externas. En ese sentido subrayan lo siguiente:

Como comentaba yo en otra ocasión, llegar usted a un lugar como la SETENA y llegar a hablar con la persona que está revisando las variables ambientales del plan regulador y que tenga una lógica totalmente prodesarrollista, Diay a usted eso le vuela la jupa y usted dice cómo diantres en una institución que tiene que velar por la protección de los recursos más bien está velando por encontrar los portillos y agujeros en los proyectos para dejarlos hacer más desarrollo, entonces es como, Diay, de locos (Entrevista personal 2-Naranjo, 2016, pág. 12).

Al respecto, se rescata el planteamiento de Harvey (2014) cuando propone que el aparato estatal capitalista legitima la formalidad de la explotación de los recursos comunes mediante negligencias y padrinajes, garantizando de esta manera un flujo constante de rentabilidad para este grupo al que hemos denominado desarrollistas, lo cual se refleja en casos como los estudiados. Aunado a ello, Merchand (2016) señala que en América Latina se dan con frecuencia casos en que actualmente el Estado-nación está "más que nunca dedicado a crear un clima de negocios benigno para la inversión extranjera que explota en forma indiscriminada los recursos naturales solo con el fin de producir un excedente exportable, y que internaliza las externalidades negativas a cargo de los recursos naturales" (pág. 158).

Estas son solo experiencias puntuales de contradicciones encontradas en la institucionalidad que supuestamente se encarga de proteger los recursos naturales y a las personas que habitan el país. Sin embargo, este abordaje institucional ha promovido acciones de organización y resistencia, ha fortalecido la participación comunitaria que permite que se tensionen las estructuras de poder social. 


\section{Bienes comunes, organización y resistencia}

Como se mencionó anteriormente, en el apartado 3.1, se evidencia en los relatos de las personas participantes un sentido de comunidad que les cohesiona y facilita la organización para la lucha. Uno de los elementos que posibilita dicha unión es la percepción que tienen sobre los recursos naturales como pertenecientes a la comunidad, por ello están en disposición de defenderlos, máxime si son entidades externas a la comunidad las que amenazan con quitar el acceso de las personas a dichos recursos. En ese sentido, Scotto y Ramalho (1997) indica que los recursos naturales se definen como bienes comunes, pues de ellos depende directa o indirectamente la vida de las personas. La autora plantea, además, que el uso de estos recursos es indivisible, es decir, no puede impedirse o limitarse su acceso para ciertos grupos.

En ese sentido, las organizaciones comunales de Potrero y Naranjo sostuvieron acciones para conservar los bienes comunes, que van desde el agua, su gestión y administración, hasta el uso de suelos que protegen su reabastecimiento. Esto se fundamenta en que estas comunidades y personas han experimentado el deterioro que acompaña las propuestas de desarrollo, cuyo discurso engañoso se devela a sí mismo conforme pasa el tiempo.

Esta toma de conciencia de quienes integran la comunidad queda evidenciada en las palabras de un vecino, líder comunal, quien denuncia la vacuidad de los discursos desarrollistas, que se basan en engaños para convencer al pueblo de que traen beneficios pero que, al final, solo perjudican:

(...) porque la gente del pueblo piensa cosas feas del proyecto ese de Las Catalinas, y lo muy triste es que, a como yo se lo dije al gerente, que me contara con los dedos de las manos personas que trabajen ahí del pueblo propiamente del pueblo y apenas hay, creo que hay cuatro personas nada más, propias del pueblo. El resto son personas ajenas al pueblo (...). De Las Catalinas, lamentablemente no hemos tenido ni un solo beneficio (Entrevista actor clave 3 Playa Potrero, 2017).

Así, estos grupos lograron canalizar sus afectos, sus preocupaciones y su disconformidad con los manejos del Estado, en acciones que apuntan a una colectividad solidaria que resiste y rompe la lógica de dinámicas de dominación y opresión (Martín-Baró, 1992). Estas acciones se articulan como fracturas en el discurso desarrollista, en donde los desposeídos logran posicionarse como interlocutores legítimos de sus propias realidades, a través de las distintas acciones políticas de participación, lo cual además genera nuevas formas de entender la relación entre los seres humanos y el espacio que habitan.

En las experiencias de Potrero y El Chayote, las dinámicas de organización comunitaria para alcanzar los objetivos propuestos fueron muy diferentes entre sí, sobre todo por las particularidades geográficas, históricas y socioculturales de cada lugar. No obstante, existen dos puntos comunes que nos interesa resaltar: primeramente, el uso de los recursos comunitarios en el ejercicio del poder como red productora de nuevas formas de generar procesos; y segundo, las acciones 
orientadas hacia las mayorías populares (Martín-Baró, 1998). A continuación, se enfatizará en estos aspectos al presentar algunas de las estrategias gestadas que las y los actores rescatan a la hora de rememorar sus experiencias.

En la situación vivida por la CDZPECH, se considera relevante la articulación de un núcleo de trabajo heterogéneo, el cual logró canalizar las preocupaciones ambientales en relación a la Zona Protectora, particularmente a partir de la convocatoria en el gimnasio de la escuela, la cual a su vez fungió como acto fundacional de dicha organización. La capacidad de diálogo y la posibilidad de alcanzar consensos en medio de encuentros y desencuentros de opiniones, sentó las bases para la consecución de su objetivo principal -el establecimiento de una ley que delimitara la Zona Protectora y que no tuviese portillos legales que la afectaran-. Dos de los miembros de esta Comisión recuerdan el proceso así:

...lo que hicimos fue presentar un recurso de amparo, nos costó montones, luego hicimos la, hicimos, reforzamos los inventarios de biodiversidad, demostramos con mapas geológicos lo que era la zona del manto acuífero (...) entonces lo que hicimos fue, nos reuníamos todas las semanas, a ver qué teníamos, revisábamos el marco legal, el marco técnico, el marco científico, presentamos un recurso de amparo, y lo ganamos, no nos dejamos, siempre nos llamaban y siempre los debatíamos y no hubo manera, hasta que por, Diay, por cosas del destino se caen solas, apareció un supuesto chorizo, una cosa ahí como muy ilícita entre la persona que iba a construir y la persona que quería que nosotros les diéramos el chance. Había la demanda era tan grande para el carajo ese, el empresario que supuestamente iba a comprar y a construir y era tan grande la presión que tenía que, que desistió de seguir el proceso, con nosotros no podía (Entrevista personal 4- Naranjo, 2016).

Entonces como que al inicio fue ok, esto fue una ley atípica lo que declaró zona protectora al Chayote, eso es que antes metían leyes en los presupuestos de la República, después la Sala IV se pronunció que eso es inconstitucional, entonces nosotros decíamos, bueno, en cualquier momento vienen y presentan una inconstitucionalidad y se traen abajo la zona protectora, entonces nosotros, a partir de eso fue que propusimos hacer una ley, entonces ya, nos sentamos en algún momento, bueno, fueron muchas reuniones [risas] pero en algún momento fue, ok, tome, aquí está este texto, trabajémoslo y entonces ya, empezamos a hacer la fundamentación y el texto legal y lo consultamos con la gente, fue muy consultado, con mucha gente... eso sí hacíamos, nosotros todo, tomen, lean, propongan, si no les parece vengan y nos cuestionan (Entrevista grupal 1-Naranjo, 2016).

En el extracto anterior, el entrevistado hace mención de cómo el desarrollo del proyecto de ley se dio de manera participativa, abierta a la comunidad, principalmente a través de redes sociales. A la vez, a nivel legislativo existió un trabajo de presentación y consulta con todas las bancadas políticas, lo cual derivó en su aprobación con el respaldo de todas.

Por último, el trabajo de la comisión se vio potenciado a través de las alianzas comunitarias con diversos colectivos, pero principalmente con el llamado Unión 
Vital $^{19}$. Con este se produjeron una serie de festivales artístico-culturales, los cuales tenían el objetivo de difundir la agenda de la Comisión y su mensaje de protección de los recursos naturales de Naranjo, en especial los ubicados en la Zona Protectora:

Sí, hubo mucho el tema después de los festivales del agua, hubo relaciones como con ciertos distritos, por ejemplo, las campañas de reforestación, las hicimos con los festivales del agua, ¿verdad? Este, sí, cosas como ese estilo. En las peñas culturales, siempre se procuró mucho el tema del agua (Entrevista grupal 1-Naranjo, 2016).

Por otro lado, en el caso de Playa Potrero, la gran respuesta comunitaria surge a partir del temor por la posible pérdida, tanto de su autonomía comunitaria para la administración del agua, como de las estructuras físicas que habían logrado edificar a través de los años gracias al esfuerzo de los y las vecinas.

Justamente, sus principales acciones tuvieron lugar al hacerle frente al ICAA y su violencia, a través de la activación de mecanismos comunitarios de solidaridad. Ejemplo de estos fueron los espacios dirigidos a la defensa de las instalaciones de la ASADA y sus tanques, a partir de que les fuesen arrebatados de nuevo a ICAA. Esto funcionó como punto de encuentro de la comunidad, lo cual profundizaría los lazos de convivencia entre quienes participaron. En el caso de las vigilias para el cuido de los pozos se dio lo siguiente:

Uno contaba una anécdota, otro un chiste, el otro llegaba por allá, aparecía alguien, llevaba una comida, las casas hacían pasteles, hacían algo dulce para los que querían y todo tan lindo lo que se vivía porque no, no, de aquí no nos vamos, ahí viene otro, yo ya me voy, pero ahí viene otro y la llamada, vea que hace falta el café y me llamaban a mí a la casa y yo y mi esposa cocinando y vaya a dejar (Entrevista personal 7- Playa Potrero, 2015).

A través de esta "reacción a lo grande" (Entrevista personal 7- Playa Potrero, 2015), se logró que el ICAA accediera a respetar la autonomía comunitaria decretando el convenio de delegación a la ASADA. Esto condujo a la desarticulación de toda la movilización de vecinos y vecinas, en quienes se dieron posiciones encontradas al pensar unos, que debería de aprovecharse el momento para hacer frente a otras problemáticas de Playa Potrero. Sin embargo, una mayoría dio por acordado que el objetivo se había alcanzado, dejando a las organizaciones representantes de la población encargarse de los emergentes.

Ambos ejemplos de la organización comunitaria permiten dilucidar cómo las personas que conformaron estos colectivos, a través de las acciones que realizaron, plantearon una forma distinta de entender el territorio que defendían, con todo lo que este implica: la relación con ese otro afectado también por un mismo problema, los recursos naturales y su uso responsable, y por supuesto, planteando una dinámica de entender la comunidad desde un lugar distinto,

${ }^{19}$ El colectivo Unión Vital se caracterizó por el trabajo de gestión comunitaria a lo largo del cantón de Naranjo utilizando
como estrategia metodológica las peñas culturales. Página oficial de Facebook https://www.facebook.com/FestivalUnionVital/ 
haciendo el intento de distanciarse de las lógicas del capital que entienden los recursos naturales como mercancía.

Dichas experiencias plantean un esfuerzo por reconfigurar el entendimiento de la relación comunitaria y su vínculo con los recursos naturales, tratando de deconstruir el discurso del desarrollo asumido ideológicamente por las dinámicas del mercado, en donde estos actores comunitarios retoman su cuota de poder social en los procesos de satisfacción autogestionada de las necesidades medioambientales, ante las cuales la economía neoliberal no puede (Leff, 2004).

¿Cuáles son los logros? Estas dos comunidades y sus protagonistas toman consciencia de cómo estas luchas y estas resistencias nacidas desde los afectos, desde la vivencia en carne propia de las consecuencias de ese "desarrollo" y desde la organización, les permitieron estar mejor, escapar de su "condición indeseable e indigna" (subdesarrollada), y que lo único que les ofrecía era "hacerse esclavos de las experiencias y sueños de otros" (Esteva, 1996, pág. 61). Por ello, retomamos, a modo de cierre de este apartado, palabras de dos personas entrevistadas en donde visibilizan lo que conciben como los logros de sus luchas:

(...) se quiso meter en una nueva ley para blindar esa declaratoria de Zona Protectora y que por dicha, bueno, se logró el objetivo y fue uno de los proyectos que quizás se haya tramitado más rápidamente en la Asamblea Legislativa y que haya contado con un amplio apoyo de todas las fracciones legislativas y precisamente porque fue esa dinámica de que fue todo el pueblo de Naranjo el que se avocó a esa defensa de ese recurso, es un tema muy sensible que por dicha se logró posicionar gracias a toda esa movilización que se dio. (Entrevista actor clave, - 2 Naranjo, 2017).

Bueno el objetivo era dejar con sed la comunidad y así sucesivamente la gente defendió, agradecido completamente de la comunidad que defendió a la junta directiva que generalmente, sí me tocó liderar el conflicto porque en esos casos al que buscan es al líder, el encargo, el apoderado generalísimo que es el presidente y sucesivamente así, la gente se unió y pueden ver en el pozo todavía las banquitas donde se hizo la vigilancia las 24 horas (Entrevista actor clave 3, - Potrero, 2016).

Queda claro que las personas de las dos comunidades, reconocen que es gracias a la resistencia traducida en acciones colectivas que se logró proteger el recurso hídrico: de no ser por eso los grandes capitales, el Estado y las instituciones habrían cedido a la presión de un modelo de desarrollo que, en el fondo, se sabe destructivo y depredador de bienes comunes, pero que se disfraza de un modelo eficaz de crecimiento económico local.

\section{Conclusiones: propuesta ético política}

Lo anteriormente descrito y analizado, parte de una propuesta teórico-ética que se opone a la mercantilización de la vida cotidiana y de las necesidades básicas de aquellas poblaciones desposeídas por la expansión de las dinámicas del mercado (Harvey, 2014). Además, es un intento por contribuir con la memoria histórica de las comunidades en sus procesos de organización, en las cuales se 
enfrentan y proponen nuevas formas de entender los entramados comunitarios y su relación con el espacio que habitan

Desde nuestra experiencia con las narrativas y memorias de las comunidades, acuerpamos las palabras de Flores (2012), quien plantea que la psicología, en este caso social comunitaria, debe ser capaz de entender las vivencias de las personas envueltas en dinámicas de opresión para generar procesos de acompañamiento en su liberación. En este caso, desde nuestro proyecto de investigación, proponemos que la sistematización de su experiencia y los productos que de ella derivan, como un intento de vincular experiencias y estrategias desarrolladas en colectivo ante amenazas de desposesión y privatización de recursos comunitarios, dentro de los cuales claramente incluimos los recursos naturales.

Nuestra propuesta metodológica parte de la comprensión de que las comunidades tienen una dimensión política, histórica y socioeconómica (Martín-Baró, 1974), la cual da lugar a la configuración de subjetividades en resistencia, contra las dinámicas voraces del mercado y sus intentos por la cooptación de los recursos y de las formas de entender las relaciones entre los seres humanos y los espacios que habitan.

Romper con este tipo de apropiaciones ideológicas, permite reinventar las formas en que hasta ahora se ha presentado la convivencia con los recursos naturales, como es el caso de la CDZPECH en Naranjo, y la ASADA de Playa Potrero en Santa Cruz. Tiempo atrás Marx y Engels ([1948] 2014) advertían cómo el capitalismo precisa revolucionar las relaciones de producción y, con estas, las relaciones sociales, para así romper con cualquier traba a la producción. Los discursos de protección a la vida y los recursos naturales generadas a partir de las experiencias aquí narradas, se pueden entender como esas trabas.

Es muy relevante recuperar el tema del poder de las organizaciones comunitarias, entendido como "aquel carácter desigual de las relaciones sociales basado en la posesión diferencial de recursos" (Martín-Baró, 1992, pág. 18), puesto que a partir de las experiencias narradas queda en evidencia como el compromiso de las personas con los objetivos colectivos es lo que hace que se geste una cuota de poder que pone en jaque el avance de los grupos socialmente privilegiados vinculados al desarrollo económico, turístico y sustentable.

Con esto, posicionamos una apuesta por visibilizar las estrategias de resistencia ante estas dinámicas de expansión del capital, que destruyen los recursos comunitarios en el que se ve el sostenimiento de la vida. Además, nos sumamos a la apuesta epistemológica de deconstrucción de la racionalidad ambiental, que apunta por hacer un uso indiscriminado de los recursos sin prever las consecuencias para las grandes mayorías:

El saber ambiental implica un proceso de deconstrucción de lo pensado para pensar lo aún no pensado, para desentrañar lo más entrañable de nuestros saberes y para dar curso al futuro por venir. Es un saber que se sostiene en la incertidumbre y en el "aún no" del saber, movido por el deseo 
de vida que se proyecta hacia la construcción de lo inédito, a través del pensamiento y la acción, en la perspectiva del infinito, la diferencia y la alteridad (Leff, 2004, pág.246).

Por ello, este texto tiene la intención de compartir experiencias comunitarias en resistencia para promover diálogos entre historias de logros y éxitos donde las personas que protagonizan y sostienen estos movimientos puedan establecer redes de intercambio y posicionarse más fuertemente en la disputa por ser interlocutores de sus realidades.

\section{Referencias y bibliografía}

\section{Entrevistas:}

Entrevista Grupal 1- Naranjo, 3 de junio 2016, 1-20.

Entrevista personal 2-Naranjo, 15 de junio de 2016, 1-12

Entrevista personas 3- Naranjo, 24 de junio del 2016, 1-12.

Entrevista personal 4-Naranjo, 15 de noviembre de 2016, 1-20

Entrevista personal 4 Playa Potrero, 5 de octubre, 2016, 1-18.

Entrevista personal 7- Playa Potrero, 2 de abril, 1-10

Entrevista personal 8- Playa Potrero, 4 de octubre de 2015, 1-16

Entrevista personal 10-Playa Potrero, 18 de noviembre de 2016, 1-15

Entrevista personal 11-Playa Potrero, 25 de abril de 2015, 1-4

Entrevista personal 14- Playa Potrero, 19 de noviembre de 2016, 1-11

\section{$\underline{\text { Bibliografía }}$}

Blanco, Edgar. (2016). Medio ambiente y desarrollo: efecto de las actividades productivas y la legislación ambiental sobre la naturaleza y las condiciones de vida de la población en la Región Chorotega de Costa Rica, 1990-2014. Diálogos Revista Electrónica de Historia 17 (2), 3-30. Recuperado desde http://revistas.ucr.ac.cr/index.php/dialogos/article/view/22797/25373

Bolaños, Cristina. (2016). Conflictos socioambientales por la gestión del agua: el caso de la comunidad Playa Potrero, Guanacaste. Tesis de licenciatura en Trabajo Social, Universidad de Costa Rica. Ciudad Universitaria Rodrigo Facio, San José.

Bran, Cinthya (2014). Vecinos de playa Potrero se oponen a llegada de AyA. La Nación, 9 de febrero 2009. Tomado de: https://www.nacion.com/archivo/vecinosde-playa-potrero-se-oponen-a-llegada-de aya/D34RRNB33JCSLBSYIPIADQ2TBE/story/

Castro, Armando. (2015). Planificación del recurso hídrico y su relación con el agua como derecho humano: el estudio de caso de la Federación de Acueductos de la Zona Protectora El Chayote. Tesis de licenciatura en Planificación y Promoción Social, Universidad Nacional, Ciudad Universitaria Omar Dengo, Heredia.

Chen Mok, Susan (2015). Turismo en el pacífico costarricense: un análisis de la oferta y demanda. Diálogos: Revista Electrónica de Historia. Escuela de Historia. Universidad de Costa Rica Vol. 15 (2), 69-108 
Cordero, Teresita. (2007). Relaciones de poder en los procesos grupales, una reflexión desde la Psicología Social Comunitaria. Psicología, globalización y desarrollo en América Latina, editado por Flores. México: Editorial Latinoamericana.

Esteva, Gustavo. (1996). Desarrollo. En Sachs, Wolfgang. (editor). Diccionario del desarrollo. Una guía del conocimiento como poder. Perú: PRATEC.

Flores, Jorge. (2012). Psicología comunitaria, opresión y exclusión. Liminales, escritos sobre psicología y sociedad 1 (2), 117-136.

Giarracca, Norma (2007). The tragedy of development: disputes over natural resources in Argentina. En Sociedad (B. Aires) vol.3 no.26 Buenos Aires 2007, pp. 2-14.

Gligo, Nicolo. (2007). Estilos de desarrollo y medio ambiente en América Latina, un cuarto de siglo después. En Revista Virtual REDESMA (1), 11-28.

Harvey, David. (2014) Diecisiete contradicciones y el fin del capitalismo. Profile Books.

INEC, ENAHO, 2010. Tomado de (fecha 09 nov 2019): https://www.inec.go.cr/sites/default/files/documentos/empleo/publicaciones/reen aho2010-02.pdf

INEC, ENAHO, 2019. Tomado de (fecha 21 enero 2020): https://www.inec.cr/sites/default/files/documetos-bibliotecavirtual/reenaho2019.pdf

Leff, Enrique. (2004). Racionalidad ambiental. La reapropiación social de la naturaleza. Buenos Aires: Siglo XXI.

Martín-Baró, Ignacio (1974). ¿Quién es el pueblo?: reflexiones para una definición del concepto de pueblo, Estudios Centroamericanos 29, 11-20.

Martín-Baró, I. (1992). Los grupos con historia un modelo psicosocial. Revista de Psicología de El Salvador, 11 (43), 7-29.

Martín-Baró, Ignacio. (1998) Hacia una psicología de la liberación. Psicología de la Liberación. Madrid: Editorial Trotta.

Marx, Karl; Engels, Federic. ([1848] 2014). Manifiesto del Partido Comunista. En H. Tarcus. (Ed.), Karl Marx. Antología (63-100). Buenos Aires: Siglo XXI Editores.

Merchand, Marco Antonio. (2016). Neoextractivismo y conflictos ambientales en América Latica. Revista Espiral, Estudios sobre Estado y Sociedad, XXIII (66), 155-192.

Montero, Maritza. (2004). Introducción a la psicología comunitaria. Buenos Aires: Paidós. 
Mota, Laura y Sandoval, Sandoval. (2016). La falacia del desarrollo sustentable un análisis desde la teoría decolonial. Iberoamérica Social: revista-red de estudios sociales (6), 89-104.

Navas, Gretel y Cuby, Nicolás. (2015). Análisis de un conflicto socioambiental por el agua y turismo en Sardinal, Costa Rica. Revista de Ciencias Sociales, (150):110-124. DOI http://dx.doi.org/10.15517/rcs.v0i150.22835

Piedra, Raquel y Rojas, Victoria (2011). Situación jurídica actual de la Zona Protectora El Chayote, a la luz del decreto ejecutivo N 35151 MINAET del 04 de febrero del 2009". Tesis de licenciatura en Derecho, Universidad de Costa Rica, Ciudad Universitaria Carlos Monge Alfaro, San Ramón.

Quijano, Aníbal. (2000). "El fantasma del desarrollo en América Latina". Revista Venezolana de Economía y Ciencias Sociales 6, no.2, 73-90.

Scotto, Gabriela y Ramalho, Angela. (1997). Conflictos ambientales en Brasil: ¿naturaleza para todos o solamente para algunos? Río de Janeiro: IBASE.

Suanes, Macarena (2016). Inversión extranjera directa y desigualdad de los ingresos en América Latina. Un análisis sectorial. Revista CEPAL, 118, 50-66.

Sunkel, Osvaldo. (1970). El subdesarrollo latinoamericano y la teoría del desarrollo. México: Siglo Veintiuno Editores. 